\title{
ЧАСТОТА ПЕРИФЕРИЧЕСКИХ ХОРИОРЕТИНАЛЬНЫХ ДИСТРОФИЙ У ДЕТЕЙ И ПОДРОСТКОВ С МИОПИЕЙ
}

\author{
Шырынбеков Н., Кафедра офтальмологии, факультет интернатуры и резидентуры, НАО \\ «Казахский Национальный медииинский университет им. С.Д. Асфендиярова, Алматы, Казахстан \\ Халиков Е., Кафедра офтальмологии, факультет интернатуры и резидентуры, $Н A O$ «Казахский \\ Национальный медицинский университет им. С.Д. Асфендиярова, Алматы, Казахстан \\ Есенов Е., Кафедра офтальмологии, факультет интернатуры и резидентуры, $Н A O$ «Казахский \\ Наииональный медицинский университет им. С.Д. Асфендиярова, Алматы, Казахстан \\ Умаров Ф., Кафедра офтальмологии, факультет интернатуры и резидентуры, НАО «Казахский \\ Наџиональный медицинский университет им. С.Д. Асфендиярова, Алматы, Казахстан \\ Толыбаева Ж., Кафедра офтальмологии, факультет интернатуры и резидентуры, НАО \\ «Казахский Наџиональный медицинский университет им. С.Д. Асфендиярова, Алиаты, Казахстан
}

DOI: https://doi.org/10.31435/rsglobal_conf/30012021/7391

Abstract. This article presents the results of the survey: There were 46 patients (86 eyes) under observation with various types of Peripheral chorioretinal degenerates aged 5 to 15 years, under observation, who were being treated at the Kazakh Research Institute of Eye Diseases. The relationship between the incidence of peripheral retinal dystrophies depending on gender, age and length of the eyeball was determined. Of these, 24 boys (44 eyes), 22 girls (42 eyes). Were identified: the most common frost-like dystrophy (31\%), somewhat more often in girls. Mixed forms of dystrophies (16\%) occur in girls 2 times more often than in boys. Dystrophy of the "snail track" type (11\%) is more often observed in girls 2.2 times. Ruptures occur in 6\% of cases, mostly in boys. Cobblestone retinal dystrophy was 5\%, only in boys. Lattice dystrophy occurred in $2 \%$ of boys. The greatest number of peripheral retinal dystrophies in prepubertal and pubertal patients is detected with an eye length of 26.0-28.0 $\mathrm{mm}$ (56 eyes).

Keywords: peripheral retinal dystrophy, myopia, retinal tear.

Введение. Периферические хориоретинальные дистрофические изменения на глазном дне, чаще возникающие на фоне миопии, приводят к разрывам сетчатки, что в последующем может осложниться развитием её отслойки. Актуальность этой проблемы усиливается ещё и тем, что данной патологией страдают в основном лица молодого трудоспособного возраста. Слепота, возникающая на фоне отслойки сетчатки, занимает 2-3 место среди всех возможных причин потери трудоспособности. Основная опасность периферических хориоретинальных дистрофий (ПХРД) и возникновения отслойки сетчатки заключается в отсутствии каких-либо симптомов на начальных стадиях заболевания, часто изменения на сетчатке являются случайной находкой при офтальмологическом осмотре [1,2]. Ранняя диагностика представляет высокую актуальность для своевременного выявления дистрофического процесса.

Предполагается, что существует зависимость частоты встречаемости дистрофических изменений сетчатки у детей в период активного роста, вызванного гормональной перестройкой $[3,4]$. В связи с этим особое внимание стоит уделять диагностике и скринингу дистрофий у детей препубертатного и пубертатного возраста, периоду роста склерального каркаса органа зрения, поэтому изучение этой проблемы у детей представляется особо актуальным [5].

Цель - выявить виды ПХРД и их связь частоты с полом и длиной глаза у детей с миопией.

Материал и методы.

Под наблюдение находилось 46 пациентов (86 глаз) с различными видами ПХРД в возрасте от 5 до 15 лет, находящихся на лечении в КазНИИ ГБ. Из них мальчиков 24 (44 глаз), девочек 22 (42 глаз). Пациентам было проведено стандартное офтальмологическое обследование, включающее визометрию без коррекции и с коррекцией, керато-рефрактометрию в физиологических условиях и после проведения циклоплегии, эхобиометрию и циклоскопию. 
Таблица 1. Распределение по видам дистрофий сетчатки у девочек в возрасте 5-13 лет (40 глаз)

\begin{tabular}{|l|c|c|}
\hline \multirow{2}{*}{ Виды дистрофий } & \multicolumn{2}{|c|}{ Длина глазного яблока } \\
\cline { 1 - 3 } & $24-25,9$ & $26-28,0$ \\
\hline След улитки & $2(5 \%)$ & $5(12 \%)$ \\
\hline Инееподобная & $6(14 \%)$ & $9(21 \%)$ \\
\hline Смешанная форма & $4(10 \%)$ & $6(15 \%)$ \\
\hline Разрыв & 0 & $1(2,5)$ \\
\hline Лазеркоагуляты & $2(5 \%)$ & $5(7,5 \%)$ \\
\hline
\end{tabular}

Таблица 2. Распределение по видам дистрофий сетчатки у мальчиков в возрасте 5-12 лет (30 глаз)

\begin{tabular}{|l|c|c|}
\hline \multirow{2}{*}{ Виды дистрофий } & \multicolumn{2}{|c|}{ Длина глазого яблока } \\
\cline { 2 - 3 } & $24-25,9$ & $26-28,0$ \\
\cline { 2 - 3 } & 0 & Количество дистрофий \\
\hline Решетчатая & 0 & $2(3 \%)$ \\
\hline След улитки & $4(13 \%)$ & $6(20 \%)$ \\
\hline Инееподобная & $1(3 \%)$ & $2(6 \%)$ \\
\hline Булыжной мостовой & $1(3)$ & $2(6 \%)$ \\
\hline Смешанная форма & $1(3)$ & $1(3 \%)$ \\
\hline Разрыв & $1(3 \%)$ & $7(23 \%)$ \\
\hline Лазеркоагуляты & & \\
\hline
\end{tabular}

Таблица 3. Распределение по видам дистрофий сетчатки у мальчиков в возрасте 13-15 лет (16 глаз)

\begin{tabular}{|l|c|c|}
\hline \multirow{2}{*}{ Виды дистрофий } & \multicolumn{2}{|c|}{ Длина глазного яблока } \\
\cline { 2 - 3 } & $24-25,9$ & $26-28,0$ \\
\hline Решетчатая & 0 & Количество дистрофии \\
\hline След улитки & 0 & $1(6 \%)$ \\
\hline Инееподобная & $1(6 \%)$ & $1(6 \%)$ \\
\hline Булыжной мостовой & $1(6 \%)$ & $1(6 \%)$ \\
\hline Смешанная форма & 0 & $2(13 \%)$ \\
\hline Разрыв & $1(6 \%)$ & $1(6 \%)$ \\
\hline Лазеркоагуляты & $5(31 \%)$ & $3(19 \%)$ \\
\hline
\end{tabular}

Результаты и их обсуждение. На 86 глазах были выявлены следующие виды ПХРД: «решетчатая» дистрофия у мальчиков - 2 глаза (4\%); дистрофия по типу «следа улитки» у мальчиков - 3 глаза (6\%), у девочек - 7 глаз (18\%); «инееподобная» дистрофия у мальчиков 12 глаз (26\%), у девочек - 15 глаз (37\%); дегенерация по типу «булыжной мостовой»у мальчиков - 4 глаз (9\%); смешанные формы у мальчиков - 5 глаз (11\%), у девочек - 10 глаз (25\%); разрыв сетчатки у мальчиков - 4 глаза (9\%), у девочек - 1 глаз (2\%). В 27\% выявлены лазеркоагуляты после лазербарража.

Наибольшее количество ПХРД выявлено при длине глаза 26,0-28,0 мм у мальчиков. Наиболее часто «инееподобная» дистрофия была диагностирована у 15 девочек - в возрасте 513 лет (37\%), у 10 (8,6\%) мальчиков - в возрасте 6-12 лет, и у 2(1,7\%) мальчиков в возрасте 1315 лет. Таким образом, данный вид дистрофии сетчатки чаще встречался у девочек. Разрыв сетчатки без отслойки диагностирован: у девочек в возрасте 5-13 лет 1 (2,5\%), у мальчиков в возрасте 5-12 лет $2(6,0 \%)$ и у мальчиков в возрасте $13-15$ лет $2(6,0 \%)$. Таким образом, разрыв сетчатки без отслойки встречался во всех группах и был характерен для пациентов обоих полов в препубертатном возрасте. 
Выводы. Наиболее часто встречается инееподобная дистрофия (31\%), несколько чаще у девочек. Смешанные формы дистрофий (16\%) у девочек встречаются в 2 раза чаще, чем у мальчиков. Дистрофия по типу «след улитки» (11\%) чаще наблюдается у девочек в 2,2 раза. Разрывы встречаются в 6\% случаев, преимущественно у мальчиков. Дистрофия сетчатки по типу «булыжная мостовая» была в $5 \%$, только у мальчиков. Решетчатая дистрофия имела место в $2 \%$ у мальчиков. Наибольшее количество периферических дистрофий сетчатки у пациентов в препубертатном и пубертатном возрасте выявляется при длине глаз 26,0-28,0 мм (56 глаз).

\section{ЛИТЕРАТУРА}

1. Виблая И.В., Захаренков В.В., Бурдейн А.В. и др. Миопия детей как актуальная проблема общественного здоровья и здравоохранения Кемеровской области // Вест. Кузбасс. научн. центра. 2010. - № 11.

2. Дравица Л.В. Состояние парного глаза у пациентов с односторонней отслойкой сетчатки // Ars Medica. - 2010. - № 13 (33). - С. 162-164.

3. Киселева Т.Н. Ультразвуковые методы исследования кровотока в диагностике ишемических поражений глаза // Вест. офтальмол. - 2004. - № 4. - С. 3-5.

4. Нефедовская Л.В. Миопия у детей как медико-социальная проблема // Росс. педиатрич. журн. 2008. - № 2. - C. 50-53.

5. Byer N.E. Lattice degeneration of the retina // Surv Ophthalmol. - 1979. - Vol. 23, № 4. - P. 213-248. 